Int. J. Electrochem. Sci., 14 (2019) 8039 - 8047

\title{
Application of Electrochemical Impedance Spectroscopy to Evaluate the Corrosion Behavior of 2304 Duplex Stainless Steel Reinforced Rebar in Concrete Exposed in Chloride-Rich Environment
}

\author{
Wu Zhao ${ }^{\text {, Jianguo Zhao }}$, Shengjing Zhang ${ }^{2}$, Jinbo Yang ${ }^{1, *}$ \\ ${ }^{1}$ College of Water Conservancy and Civil Engineering, Shandong Agriculture University, Taian, \\ 271000, China. \\ ${ }^{2}$ Shandong Luzhu Cement Co. Ltd., Taian, 271400, China. \\ *E-mail: yangjinbo@tsinghua.org.cn and yangjinbotsinghua@aliyun.com
}

doi: $10.20964 / 2019.08 .53$

Received: 26 March 2019 / Accepted: 24 May 2019 / Published: 30 June 2019

\begin{abstract}
Corrosion of steel bars embedded in concrete is one of the main causes affecting the long-term performance of reinforced concrete structures. In this study, the corrosion behavior of AISI 2304 stainless steel reinforced calcium silicate cement concrete in chloride-rich environments were evaluated by electrochemical impedance spectroscopy (EIS). The EIS results show that both the immersion time and $\mathrm{pH}$ play significant roles in the evolvement of the charge transfer processes and film resistance. At $\mathrm{pH}$ value of 13, the total impedance increased during the 3 months of immersion time, and then it slightly reduced, indicating the protective ability is being lost. The calcium silicate concrete with steel rebar indicated that the samples remained in the passive state throughout the linear polarization resistance test. The polarization resistance value attained in the $\mathrm{pH}$ solutions of 13 are upper than that in other $\mathrm{pH}$ values which show higher capability for corrosion prevention in the $\mathrm{pH}$ value of 13 .
\end{abstract}

Keywords: Calcium silicate cement; AISI 2304 stainless steel rebar; Chloride-rich environments; Electrochemical impedance spectroscopy; Linear polarization resistance

\section{FULL TEXT}

(C) 2019 The Authors. Published by ESG (www.electrochemsci.org). This article is an open access article distributed under the terms and conditions of the Creative Commons Attribution license (http://creativecommons.org/licenses/by/4.0/). 